\title{
ASPECTS OF SCIENTIFIC RESEARCH IN MILITARY SCIENCES
}

\author{
Lucian Valeriu SCIPANOV ${ }^{*}$, Florin NISTOR ${ }^{b}$ \\ ${ }^{a, b}$ Carol I National Defense University, Romania
}

DOI: $10.24818 / \mathrm{IMC} / 2020 / 05.04$

\begin{abstract}
This study attempts to identify the most common research methodology at university and postgraduate levels, which meets the research needs related to the scientific level addressed in the fields of Military Sciences, Intelligence, Security and Defense. In the military sciences domain, the most common research techniques are both quantitative, and qualitative, which should be correlated with the research tools according to the hypothesis, the objectives and the thesis, as set by the researcher. This study aims to analyze the possibility of using the following specific terms in the field of scientific research, that are related to the levels of approach, fragmentation, and synthesis of the research: types of research; research methods; research techniques; research procedures; research tools; research method; research directions; thesis; hypothesis and objectives Therefore, the novelty of the output of this pilot study is to create a procedural framework regarding the application of the best, most appropriate methods, adaptable research needs specific to works in the field chosen by bachelor's degree, master's degree and doctoral students. The practical application of the results of this study will be implemented by our course members, bachelor degree, master's degree and doctoral students, as long as the above mentioned methods will represent research benchmarks structured on the objectives and directions of research particular to the principles of military art.
\end{abstract}

KEYWORDS: military science, procedural framework research method.

\section{INTRODUCTION}

Considering the concerns of the teaching staff, researchers, doctoral students and education experts regarding the production of high-quality papers, which serve the education area and experts alike, the authors consider such an approach is useful in order to support the latter by structuring information and standardizing the language specific for researchers in the areas of Military Sciences, Intelligence, Security and Defence. Therefore, this approach is intended to identify the most common research methods which underlie a research methodology at the university and postgraduate levels, and represent the optimal framework to separate on a scientific basis the research concerns adjacent to the selected level.

The areas of Military Sciences, Intelligence, Security and Defence belong with the social sciences which tackle a certain aspect of the human activities regarding the provision and preservation of national security, the defence of the territory and the salvgardation of the state's sovereignty and independence.

The scientific research in these fields does not refer to particular aspects of engineering sciences related to thechnology, but rather to the interpretation of the phenomena connected to the development of military art, the application of the laws and principles of the armed conflict, to predictions and estimates regarding the effects the latter produce. In other words, the aim of the

\footnotetext{
* Corresponding author. E-mail address: shcipio@yahoo.com
} 
scientific research in the areas of Military Sciences, Intelligence, Security and Defence is to identify the armed conflicts physiognomy, to study the military-society relationship, to suggest methods of optimizing and adapting the way in which some principles, forms, procedures and norms are applied in these areas.

Although the research methods are borrowed mainly from the domain of humanities and social sciences, the hands-on experience gained in the research for the benefit of education helped us to notice that the military domain uses methods which have crystallized into a nucleus specific for this field, a reason for which the authors intend to delineate and disseminate it. This study approach will be useful to our course members, bachelor degree, master's degree and doctoral students, as long as the above-mentioned methods will represent research benchmarks structured on the objectives and directions of research particular to the principles of military art.

In order to develop research, the first stage aims to identify the most common research methods in the areas of Military Sciences, Intelligence, Security and Defence. Later on, is going to outline the elements specific for research by identifying the adjacent techniques, procedures and instruments particular to the research methods identified thereby and by which the research objectives can be met.

Once such an approach initiated, is needed to start by the introspection of the domain. The related scientific research is the starting point of our approach; that is why is needed to briefly stress out some aspects.

\section{SCIENTIFIC RESEARCH}

In general terms, research is a systematic process, intuitive or accidental sometimes, in the quest of new knowledge, which unfolds in different areas of science, within some academic subject matters and is conducted by researchers in the strict observance of research and innovation-related ethical norms (Romanian Law 206/2004). In other words, the research activity refers to getting results meant to enlarge knowledge. Research is a scientific activity if its results are acknowledged by the public at large, especially the academia; otherwise, the research activity may be mistaken for a factfinding attempt, meant to answer concrete questions. Research itself is completed by the dissemination and take-up of its results. The dissemination of research results is the approach the researcher performs to popularize the partial and final results of the scientific approach, in order to submit them to constructive dialectical disputes, to validate and to harness them in different areas of knowledge. Popularization of the results is the awareness and comprehension of their benefits by the public at large.

Scientific research should meet the following conditions: to have well-defined research goal and aims; to lead the researcher by means of the research plan to carrying out the objectives; to observe the accuracy and originality of the data presented; to use research methods, techniques and tools throughout the analysis, related to the research goal and aims; to lead to relevant and well-supported conclusions, in line with the results; and, the researcher to be honest, competent and pursuant of the research conduct. "Quality must be understood as a final product of the interaction between students, teachers, and the institutional environment in which the learning process takes place" (Gora, 2018). The same thing happens in research if it takes place in the university environment and both students and teachers participate together.

Generally speaking - epistemology-wise - the following specific terms are known in scientific research, adjacent to the levels of approach, fragmentation and synthesis of research: types of research; research methods; research techniques; research procedures; and, research tools.

\subsection{Types of research}

The types of scientific research identified following the analysis of the humanities and social sciences area are as follows: theoretical research and empirical research (Chelcea, 2001a). 
Theoretical research is a fundamental, conceptual research, a pure one from the innovation viewpoint, due to the method used, the contribution it brings to science and the cutting edge impact on the field. This type of reaserch builds on abstractization - harder to grasp in absence of prior knowledge of research specificities, or of explanatory models, easier to grasp and accept.

Empirical research consists in observation of the domain by direct incursion into the objective reality. Given the nature of research, the latter can be quantitative and qualitative. Empirical research builds on defined theoretical models and concepts, by which theory is cross-checked in order to contribute to the conceptual enrichment of the domain under investigation.

Quantitative empirical research is used in microanalyses by means of data collection and processing through experiments, surveys, interviews, questionnaires, observations, etc. During such research, in order for the product to be relevant, a large number of data is needed for processing and analysis; therefore, this type of research is an extensive one, leading to the enlargement of the knowledge repository. The data collected come from primary sources, if directly identified by the researcher, or from secondary sources, if partially or totally processed and supplied by a third-party. This type of research is an improvement one, through which the researcher may check the working hypotheses efficiency.

Qualitative empirical research is used in microanalyses which do not observe the statistical rules, as it follows attributes associated with the element sunder research. Following the analysis conclusions are reached, the cause-effect relationship is seen, concepts are derived and the leap from theory to practice is made. This type of research is an intensive, fact-finding one, by which a deeper understanding is achieved. During qualitative research, the researcher should be creative and may use different types of analysis: theme-based analysis (on a timely topic and the consequences it might have); comparative analysis (which compares the information coming from several sources); content analysis (of the answers to questionnaires or the interpretation of the extracted or decoded information), discourse analysis (more technical, referring to the use of certain words, texts, terms, etc.).

\subsection{Research methods}

The method is a means of identification of a fact, truth, or reality.The term derives from Greek (methodos), which refers to a way or means of solving a problem, a way of stating reality. The method is a set of rules and knowledge principles, of statement and transformation of reality. The method is also linked to the approach by which some answers are looked for, to the discovery of some generally valid aspects, usually answering the question how, meaning the way in which that answer can be found. In the field of humanities and social-sciences, the research method refers to the way by which new solutions, paths, itineraries are identified, as to the goal of the action. The method should identify the link between theory and practice, for most of the times, without much explanation, the method derives from a theory and can be cross-checked in practice.

In our opinion, the method is the way of thinking (in connection with the research strategy) and has a technique or techniques of application associated to it within the approach initiated by the researcher.

The typology of research methods is done in keeping with certain criteria: the time criterion; reactivity; the intrinsic characteristic; the place and role inside research; the goal (Chelcea, 2001a). Depending on the time criterion, three main research methods can be identified: cross-sectional; longitudinal and horizontal (Chelcea, 2001b).

Cross-sectional research is performed in order to determine the specific trait of a phenomenon, the relations between subjects, the assessment of a phenomenon, at a certain point.

The identified cross-sectional research methods are: observation; inquest; test; description: e. g., the identification of the relationship and correspondence of the specific steps of military action planning levels depending on the echelon at which operational collaborative and parallel planning is made. 
Longitudinal research is used to observe the evolution of phenomena in time, by comparing the same elements specific for the phenomenon under research. The identified longitudinal research elements are: the test; the case study; the biography; observation; the comparison. As an example, the identification of the long-term evolution of the operational planning process.

Horizontal research presupposes the analysis of independent phenomena by successive observation, under the same research circumstances. The methods of horizontal research are: observation; inquest; test; interview. These are finding-based methods. For instance, the identification of similarities and differences regarding the implementation of the operational planning process in different military schools of thought or at different echelons, structures and services.

The reactivity criterion in research refers to the degree of interaction between the researcher and the subject of research. If the former intervenes on the latter, we talk about experimental research. If the former supervises or supports the patter but does not intervene directly to influence reactions, we talk about quasi-experimental research. If the former does not intervene on the latter, we talk about observational research (Chelcea, 2001b).

The intrinsic characteristic defines the quantitative and qualitative research methods, detailed under the empirical research section, during the scientific approach.

Depending on their place and role within the research process, could be identified the following methods: data collection methods (observation, experiment, test); data processing methods (analysis, historical method); data interpretation methods (prediction, forecast).

Depending on the goal of research, are identified the following methods: descriptive methods and research (forecast, intuition, assumption); explanatory methods and research (Chelcea, 2001a), fundamental methods; applicative methods (Chelcea, 2001b).

To conclude, are considered three components of scientific research are: the goal, the method and the object of research (phenomena, laws, concepts, etc.). The scientific research works based on some laws and principles which rule the domain and which the researcher must apply and respect in order to reach the desired goal, that ist o discover the scientific truth.

\subsection{Research techniques}

The term technique comes from Greek (tekne) and represents a set of rules and methodological procedures, meant to reach a goal. Therefore, the research technique is a methodology of how to approach research. To understand the relation between the research method and technique, let us mention that a research method relies on different research techniques, which can be applied differently and are conducive to reaching the research-related objectives. From the authors research experience, can be concluded that the most common research techniques are: the questionnaire; the interview; observation; the experiment; the study; the inquest; the survey; the case study, etc, (Chelcea, 2001b).

In the military sciences domain, the most common research techniques are both quantitative (data collection; fact-finding research and analysis; content analysis, conceptual development analysis), and qualitative (data processing and interpretation; conceptual modelling; inferences and inductions), which should be correlated with the research tools according to the hypothesis, the objectives and the thesis, as set by the researcher.

In conclusion, if the method is a research strategy, the technique builds on a tactics by which the research strategy objectives are carried out.

\subsection{Research procedures, tools and hypotheses}

The procedure is an element pertaining to the technique, which allows for getting straight to a certain result the researcher pursuits in a specific manner, by using some tools and by complying with some procedures, successive operations and practical solutions. Among the commonly used procedures could be mentioned: statistics; estimate; classification; orientation; clustering, etc. 
Research tools are material and means with which the researcher performs the analysis, storage, registering, comparison, data recording adjacent to research, followed by the assessment, conclusions and dissemination of the research results.

The hypothesis is a provisional causal statement, an assumption, resulting from logical reasoning or based on an inference specific to the researcher, which connects the research goal to the objectives and results, guiding the research unto empirical verification. Epistemology-wise, hypotheses can be descriptive (which describe suggestively), guiding (constructive) and explanatory (causal). All three can be: confirmative and unconfirmative, testable and untestable. The research hypothesis is not the same as the working hypothesis, which commonly is a statement based on a statistically confirmed reality and thereby contradicts the data already demonstrated and confirmed.

In the authors opinion, the process of building a research strategy usually comprises: the choice of the topic; the definition and clarification of the issue to be researched (phenomena, laws, concepts, notions, terms, methods, procedures, etc.); the definition of the research goal; the identification of research guidelines; the submission of hypotheses; the definition of the research objectives; the selection of some methods by which the research is carried out; the research itself; the validation/invalidation of hypotheses; the achievement of the research goal and objectives by the release of results; conclusions.

\section{PROPOSALS FOR RESEARCH METHODS AND TECHNIQUES IN THE MILITARY SCIENCES AREA}

The scientific research relies on three components: the research goal, the research method and the research object (phenomena, laws, concepts, etc.).

The scientific research works based on some laws and principles which rule the domain and which the researcher should apply and observe in order to reach the research goal. Generally, it can be seen that in science can be an adaptive pressure (Tiţă, 2019) that has an impact on the common methods of research, so that military science research can be influenced, too.

In the case of military sciences, more precisely in the field of military art, scientific research falls under the empirical type (Duţu, 2012), building on the researcher's group or personal experience, which - by the effects produced - has contributed to the development of scientific knowledge. In military art, for instance, the specific area-related scientific research relies on descriptions of reality (descriptive knowledge), descriptions of the military action specific phenomena. Prediction (predictive knowledge) is a military art specific research method, especially when the evolution of military ar tis analyzed and estimated. In case of analysis and submission of proposals or suggestions likely to influence the domain under research, we deal with a causal research (causal knowledge) (Duţu, 2012).

The touch with current reality (Duţu, 2012) allows researchers in the field of military art to notice events and developments of the domain, to define logical-inductive and logical-deductive judgements of the historical and conceptual type.

The acceptance of the genuine reality (trancendental) (Duţu, 2012) allows the researcher to compare and process the data, to identify differences, to discover and accept reality, in order to articulate relevant conclusions. In the military art research, elements belonging to the ontological domain of volition, physical potential or human resources necessary to participate in military actions can be used. Moreover, the research can be complemented by some aspects coming from the axiological domain from the viewpoint of the theory of value and the sense of military art with a view to delivering the working hypotheses and reaching the objectives. Last, but not least, the nomological research can be used, in order to word the definitions of terms and to achieve the conceptual links among them. In order to carry out the research objectives, some longitudinal and cross-sectional research methods originating in the sociological area (Duţu, 2012) but applicable to the military sciences can also be used, as follows: 
- the data collection method (empirical method) by fact-finding analysis, observation and analyses of the specific domain and phenomena, data processing by data framing, ranking on certain criteria and correlation of the data identified with the existing theoretical meanings; the method allows us to word definitions of military art specific concepts, to structure the data and and some conclusions;

- the historical method, which looks into the phenomenon in its development by comparing it to similar events, which leads to the identification of the way some military actions unfold in the national design or that of some international actors;

- the nomological research method, which leads to wording some definitions of concepts specific to military actions, to framing some concepts and accomplishing some conceptual links among the terms described;

- the cognitive-structural method, applied by comparing the differences, data framing, semantic and, sometimes, terminology analysis, allows for the conceptualization of terms and the optimization of conclusions;

- the referential research method allows for the identification of concepts on the phenomenon under research, so that the research technique is interpretive, and leads to drawing conclusions;

- the analysis method is used throughout the research and allows for the construction of the whole content and argumentative support of the research;

- the deductive method applies through a logical-deductive judgement, starting from generally accepted characteristics meant to identify the specific features of military actions;

- the induction method is applied by the historical-type logical-inductive judgement and allows for making proposals following the analysis of the strategies, concepts, principles and theories under research as well as of the military actions. This method helps us generalize and conceptualize specific repetitive particular high impact elements and with a view to their practical use.

\section{CONCLUSIONS}

Following the arguments, can be noted that the research procedure and technique derive from the chosen research method, which builds on a well chosen strategy. In other words, the research strategy should be an optimal mixture between methods, techniques, rules, principles, tools, in accordance with the research goal and objectives, and relying on overall knowedge.

The method is illustrative of the way of thinking (correlated with the research strategy) and has an appropriate application technique or techniques in the approach the researcher has initiated. To conclude, the method is a research strategy, whereas the technique relies on a tactics by which the objectives of strategy are carried out and the research hypotheses are validated.

The demonstrative and cognitive goal of the scientific approach is to validate and disseminate the research results. To carry out the research goal, epistemological foundations related to the origins, present status, general traits, goal, methods, means, as well as specific features of military art can be approached, which lie at the basis of the domain of scientific research.

The limitations of completing such an approach lie within the framework of constraints and restrictions, which compels the researchers to identify the niche opportunities in order to reach the intended objectives. Despite all restrictions, the researcher in the field of military art should use only information for the public at large, being forced to efficiently structure, conceptualize and disseminate it as articles and scientific papers, validated by the academia.

\section{REFERENCES}

Law no. 206/2004 on good conduct in scientific research, technological development, and innovation, with subsequent modifications and completions. 
Chelcea, S. (2001a). Metodologia Cercetării Sociologice, Bucharest: "Ed. Economică” Publishing House.

Chelcea, S. (2001b). Tehnici de cercetare sociologică, Bucharest: "SNSPA” Publishing House.

Duţu, P. (2012). Metode şi tehnici de cercetare sociologicăa, Bucharest: Publishing House of the National Defense University "Carol I".

Gora, A. A., Popa, I., \& Ștefan, S. C. (2018). Quality Management in Higher Education System: a Literature Review, Proceedings of the $12^{\text {th }}$ International Management Conference, Bucharest, Romania.

Tiţă, S. M. \& Neştian, A. Ş. (2019). Comparative analysis of scientific research performance of some romanian faculties of economic sciences, Proceedings of the $13^{\text {th }}$ International Management Conference "Management Strategies for High Performance", Bucharest, Romania. 